\title{
CONSTITUCIÓN Y SOCIEDAD: UNA REFLEXIÓN ACERCA DE LA CRISIS DEMOCRÁTICA Y DEL CONSTITUCIONALISMO CON ESPECIAL REFERENCIA AL CASO COLOMBIANO*
}

\author{
Constitution and society: an insight on the democratic \\ crisis and constitutionalism with particular reference to the \\ Colombian case
}

\author{
Constituição e sociedade: uma reflexão sobre a crise \\ democrática e o constitucionalismo, com especial referência ao \\ caso colombiano
} Vladimir Rodriguez Sanabria
rodriguez_vladimir@hotmail.com

Fecha de recepción: 15 de octubre de 2019 Fecha de revisión: 26 de octubre de 2019 Fecha de aceptación: 4 de noviembre de 2019

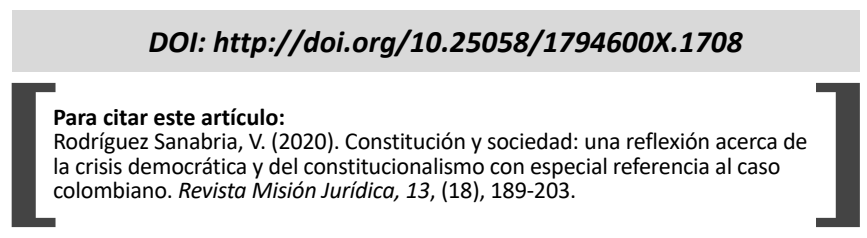

\section{RESUMEN}

Desde sus albores, la democracia ha estado en una constante crisis y ello ha afectado tanto la manera de entender a las constituciones que se han instaurado en la reciente historia de occidente como al desarrollo del constitucionalismo. Esto ha significado que también entren en crisis los proyectos de Estado surgidos en el devenir histórico. En la actualidad, el desafío democrático radica en superar las dificultades de la dinámica política y, fundamentalmente, del populismo que ha hecho carrera en el continente latinoamericano y, más aún, en la realidad colombiana. Finalmente, se indica como manera de estudio, para el caso colombiano, el abordaje desde el contexto del lenguaje por cuanto permite descubrir las honduras y falencias del proyecto nacional $\mathrm{y}$, con ello, alumbrar la explicación de la crisis democrática de nuestro país.

\section{PALABRAS CLAVE}

Democracia; constitución; constitucionalismo; crisis democrática; estados; participación ciudadana; populismo; proyecto nacional.

\footnotetext{
* Artículo de reflexión.

a. El autor del articulo ha sido profesor en la Universidad Católica de Colombia y Cooperativa de Colombia, actualmente Conjuez de la Sala Disciplinaria del Consejo Seccional de Cundinamarca, ha sido asesor de asuntos disciplinarios y en alcaldías municipales. Ha publicado un libro titulado "Estudios del Honor como objeto de protección penal", así como artículos de derecho en la Universidad Católica de Colombia y en la Revista Latinoamericana de Derecho Penal y Criminología. También es especializado en Gestión y Desarrollo Municipal y Departamental. Actualmente es maestrando de Filosofía del Derecho de la Universidad Libre.
} 


\section{ABSTRACT}

From an early stage, democracy has been in continuos crisis. This situation affected the way to comprehend the Constitutions that have been established in recent western tradition as well as in the development of the constitutionalism. This also meant the crisis of the projects of States that have appeared throughout history. Currently, the democratic challenge is to overcome the tribulations of the political dynamics and, basically, of the populism that has made a career in Latin America and, especially, in Colombian reality. Finally, for understanding the Colombian case, it is suggested an approach from the context of language because it permits the discovery of the depths and failures of the national project and, from this, to explain the democratic crisis in our country.

\section{KEY WORDS}

Democracy; Constitution; Constitutionalism; democratic crisis; States; citizen participation; populism; national project.

\section{RESUMO}

Desde o início, a democracia tem estado em constante crisec e isso tem afetado tanto a forma de entender as constituições que foram estabelecidas na história recente do Ocidente quanto o desenvolvimento do constitucionalismo. Isso fez com que os projetos estatais que surgiram no histórico também entrassem em crise. Hoje, o desafio democrático reside na superação das dificuldades da dinâmica política e, fundamentalmente, do populismo que fez carreira no continente latino-americano e, além disso, na realidade colombiana. Por fim, indica-se como forma de estudo, no caso colombiano, a abordagem do contexto da linguagem, na medida em que nos permite descobrir as profundezas e deficiências do projeto nacional e, assim, iluminar a explicação da crise democrática em nosso país.

\section{PALAVRAS-CHAVES}

Democracia; constituição; constitucionalismo; crise democrática; estados; participação cidadã; populismo; projeto nacional.

\section{INTRODUCCIÓN}

Este artículo pretende abordar las diferentes clases de Estado constitucional que se han presentado a lo largo de la tradición occidental, teniendo como contexto la crisis democrática como eje problemático para la consecución plena de la dinámica política que debería advenirse una vez instalando el constitucionalismo, pero también, dicha crisis sirve como una base desde la cual los Estados van surgiendo y reconfigurándose, sobre todo en lo atinente a la conquista de derechos y libertades. De esta manera, el estudio comienza con el abordaje de los primeros Estados modernos de derecho legal aparecidos como consecuencias de las revoluciones francesas y norteamericanas, pasando por los estados liberales-conservadores de la primera mitad del siglo XIX, también a los estados sociales de la época de las revoluciones igualmente sociales de finales de la misma época, llegando hasta los más recientes estados sociales y de derecho de la actualidad.

Con este telón histórico de fondo se introduce la dinámica democrática como crisis, pero también como motor de desarrollo y de avance del constitucionalismo para, con ello, también hacer la crítica a la realidad del Estado y constitucionalismo colombiano. En este sentido, se analizan postulados como la relación democracia-constitucionalismo, la realidad actual de los votantes o la cobertura de los derechos, el populismo, entre otros, en cuanto factores que conforman la crisis democrática. Visto este escenario, se continua, entonces, con la plurimencionada crisis democrática como explicación de las dificultades que ha tenido el Estado social y democrático de derecho para irrumpir de manera efectiva en la existencia social y jurídica colombiana, con el añadido del panorama lingüístico como apoyo para comprender de mejor manera las vicisitudes que padece la democracia y, por ende, el constitucionalismo, para tener vigencia en el plano social de Colombia.

\section{CUESTIÓN PREVIA: LA CRISIS DEMOCRÁTICA EN EL CONSTITUCIONALISMO}

En el ejercicio democrático surgió la constitución y con ello, modernamente, el constitucionalismo. Al mismo tiempo, la democracia en su desarrollo se ha mostrado constantemente en crisis por cuanto es asaltada por intereses que no tocan con la comunidad o, más recientemente, por populismos de toda 
clase. En este sentido, el presente artículo pretende mostrar cómo se ha ejemplificado la crisis democrática en los distintos proyectos de estado constitucionales que han existido en la historia moderna y temprana dentro de la tradición occidental, en orden a denotar si estamos en el camino del avance o del retroceso. Así, por ejemplo, el origen de la constitución moderna y la actitud constitucionalista tienen como raíz común, la de consolidar una aspiración general de principios y derechos con vocación popular que venía en latencia desde los albores de la modernidad hasta su plena eclosión en la Revolución norteamericana y la Revolución francesa ${ }^{1}$

Ello indica, entonces, que la constitución y el constitucionalismo, beben en movimientos emancipadores con finalidades reivindicatorias de derechos y libertades del hombre entendido como ciudadano con capacidad de autodeterminarse $\mathrm{y}$, en consecuencia, con poder para deliberar $\mathrm{y}$ decidir de manera conjunta sobre el gobierno y el futuro de la comunidad en la que vive. Ahora bien, para que esto tenga éxito, la condición ineludible es la práctica democrática, es decir, la posibilidad abierta para que los ciudadanos desde sus derechos de participación y decisión política se den su forma de Estado y, también, con la facultad para consagrar aquellas garantías que consideren necesarias para su existencia individual y colectiva junto con su correspondiente enunciación de protección respecto del poder estatal que la misma ciudadanía ha creado.

Con todo, la democracia entendida bajo las anteriores consideraciones, no surge como la base más solida sobre la cual se justifique la pretensión constitucional de erigirse como expresión de la voluntad del pueblo, pues la práctica política deforma la prístina aspiración participativa popular, transformándola en la defensa de los designios e intereses de los movimientos políticos ${ }^{2}$. En este contexto de crisis democrática, se presentarán, entonces, las variaciones de la constitución en cada modelo de Estado que la

1. Ver, en este sentido, el panorama que coloca Cassiser, en cuanto los ilustrados franceses y los padres de la revolución norteamericana, no plantearon ninguna novedad, sino que recogieron las ideas que mucho tiempo antes ya estaban ahí, y ellos se dispusieron a la acción y a lograr las aspiraciones del sentimiento general que predominaba en la época. Más en Cassiser (2013: 209).

2. Sobre ello, Touraine, 2006: 48 dialéctica de la historia ha ido construyendo, que van desde las esperanzadoras conquistas de las revoluciones de finales del siglo XVIII hasta las sociedades industriales de la actualidad. A ello, se le adjuntará como reflexiones finales, la necesidad de tener en cuenta la real estructura de la sociedad, sus visiones e ideales y, concretamente, en el caso colombiano, cómo afecta esta realidad al proyecto de nación y, por ende, a la democracia $\mathrm{y}$ al constitucionalismo.

\section{EL ESTADO DE DERECHO LEGAL}

En líneas generales, el Estado de derecho legal es consecuencia de la Revolución francesa, modelo que penetra en la Europa occidental y sobre el que se apoyarán las posteriores constituciones latinoamericanas ${ }^{3} \mathrm{y}$, desde luego, fue el primer modelo de estado que surgió producto de las revoluciones y en el que también se instauró su Constitución. Ya, específicamente hablando, el modelo constitucional en esta clase de Estado se sostiene en los deseos de la burguesía que bajo el signo de la ideología liberal buscaba, sobre todo, que se garantizaran los derechos y libertades individuales y que también se erigieran como limite efectivo contra el poder del Estado ${ }^{4}$. partir de aquí se dan, entonces, las notas características de la constitución inspirada en el modelo liberal-burgués. De esta manera, se establecieron conceptos que aún perduran, como la separación de poderes, el ejercicio de las libertades políticas, la igualdad ante la ley o la conformación del poder estatal mediante procesos electorales de participación popular ${ }^{5}$, pero además de lo anterior, la característica mas importante es vincular la actuación del Estado al principio de legalidad para que mediante ello se limitara la acción del Estado frente al individuo, especialmente para preservar la libertad de acción del ciudadano ${ }^{6}$. De hecho, la peculiaridad más relevante que surge en el Estado de derecho legal es la ordenación de todas las actividades del poder estatal a la legalidad, principio que se mantiene hasta hoy y que se invoca frente a las actuaciones desbordadas u omisivas del Estado o de sus agentes. Ahora bien, estos importantes logros para la ciudadanía estaban llamados a que
3. Ver Vigo, 2012: 23.
4. Ver Sachica, 1994: 66.
5. Ver Sachica, 1994: 67
6. Ver, Zagrebelsky, 2016: 28. 
fueran ejercitados por una sola clase, en este caso la burguesía emergente, que una vez desplazada la nobleza del poder político y promulgada la Constitución, consideró, de manera natural, ocupar el espacio estatal para la preservación de las libertades del individuo.

No obstante, los derechos promulgados en la época de las revoluciones no tuvieron vocación universal, pues, de ellos no fueron titulares las mujeres o aquellos que no tenían propiedad, tampoco se incluyeron a los negros y los indios en el caso norteamericano ${ }^{7}$. Con esto queda claro que los derechos y libertades plasmados en las primeras constituciones, producto de los movimientos emancipatorios, tienen una raigambre individualista y liberal con marcada propensión a evitar la injerencia del Estado en el libre intercambio de bienes y servicios. Lo anterior, desde luego que no demerita el genuino interés de las revoluciones, sobre todo de la francesa, de consolidar un espíritu democrático para la dirección del Estado y para las libertades del individuo, sin embargo, debe admitirse que ya estaba haciendo carrera la tendencia burguesa como contenido constitucional. De hecho, muy pronto quedó claro que el Estado de derecho fundado se había erigido para servir a la nueva clase burguesa y dominante en la esfera política y, por ende, la participación democrática no operaba para todos los ciudadanos. De esta manera, el Estado se convirtió en una entidad personificada que ya actuaba bajo sus propios fines sin consultar la voluntad del pueblo ${ }^{8}$.

\section{EL ESTADO LIBERAL CONSERVADOR}

Mientras el proceso revolucionario norteamericano consolidó la práctica democrática con la representatividad parlamentaria federal $\mathrm{y}$ un gobierno presidencialista, en Francia, la revolución se transformó en un gobierno autoritario cuyo fin principal era la persecución y eliminación de los opositores al nuevo régimen que fue tomando posiciones cada vez

7. Ver al respecto, Ruiz, 2002: 289.

8. En este sentido resulta ilustrativo el siguiente párrafo de Bertrand Russell quien al respecto escribía: "El Estado es una abstracción. No siente ni placer, ni dolor, no tiene ni esperanzas ni temores, y lo que consideramos sus propósitos no son, en realidad, sino los propósitos de los individuos que lo dirigen. Si en lugar de pensar en abstracto pensamos concretamente, en lugar de "el Estado", veremos a determinados individuos que disfrutan de más poder del que corresponde por lo general a la mayoría de los hombres" (Russell, 2005: 116). más radicales ${ }^{9}$. El natural fin de este régimen fue su propia caída, debido a sus excesos en la búsqueda de implantar un nuevo estado de cosas. Sin embargo, estos excesos, al parecer no fueron suficientes y se consagró la figura de Napoleón Bonaparte como continuador del legado revolucionario, quien, finalmente, volvería las cosas del Estado hacia el autoritarismo bajo la creación del Imperio Frances refrendada en constituciones revolucionarias, pero en todo caso, respondían al autoritarismo del emperador Bonaparte ${ }^{10} y$ que, al igual que el régimen anterior precipito su propia caída.

Con todo, ya era irreversible el hecho, según el cual, la organización política debía conformarse desde la Constitución. Esta situación, junto con la violencia y el desorden surgidos de las guerras revolucionarias y contrarrevolucionarias, motivaron a hallar puntos de encuentro entre las ideologías antagónicas dando paso al Estado liberal-conservador. En efecto, a ambas tendencias les preocupa el control del poder político por medio de la constitución y, aquí cobra sentido la unión de estas ideologías para defender, entonces, el carácter superior del principio de legalidad y la división de poderes, incluso con la capacidad de hacer prevalecer la constitución sobre la voluntad popular ${ }^{11}$, discurso este, que ha hecho carrera y que surge cada vez que se tratan de hacer intentos de reforma constitucional cuyo origen no sea de base liberal o conservadora. Así las cosas, en el Estado liberal-conservador, la constitución toma el lugar de ordenador y fuente de poder estatal, sustituyendo el lugar que tenía el Estado y también ejerciendo la soberanía ${ }^{12}$ que, ahora, posee por virtud de la hipotética expresión de la voluntad del pueblo en los mandatos constitucionales.

Esta atmosfera resultó, a la larga, en sujeción y orden. Además, era demasiado asfixiante para las reivindicaciones sociales que se preveían y que a la postre iban a desembocar en nuevos movimientos revolucionarios. Así pues, en este modelo, el Estado resultó ser un poder pasivo que solo daba cuenta del cumplimiento de la normatividad constitucional y del efectivo desarrollo del principio de legalidad, es decir, en
9. Ver Araujo, 2015: 307.
10. Ver Araujo, 2015: 308.
11. Ver, en tal sentido, Arranz, 1998: 60.
12. Ver, sobre ello, Zagrebelsky, 2016: 12. 
términos concretos, protección de la autonomía del individuo y mantenimiento de una igualdad efectiva jurídica, pero sin aludir a las condiciones por las cuales se podía llegar a gozar de autonomía y mucho menos de lograr igualdad. El Estado liberal-conservador es ajeno a los nuevos contenidos que la sociedad va formando en su propia dinámica, hecho que en la actualidad se ejemplifica en movimientos reivindicatorios que promueven el reconocimiento de novedosas pautas sociales como contenido constitucional, así como la ampliación de la participación ciudadana en la reforma de la Constitución y en las decisiones del Estado.

\section{EL ESTADO DEMOCRÁTICO DE DERECHO}

La estela de conveniencia política practicada por el modelo de Estado liberal-conservador que nació con la bienintencionada tarea de poder orden y control, terminó deslegitimándose en cuanto no permitía la irrupción de partidos o movimientos políticos distintos a la ideología liberal-conservadora, con lo cual, la primera damnificada es la practica democrática y, en consecuencia, el desarrollo constitucional, pues de la participación popular depende el carácter democrático de la constitución. Así pues, el Estado democrático de derecho responde a este cuestionamiento y su primera labor es cambiar entonces de prioridades, en efecto, la primera labor del Estado es la reconstrucción de su legitimidad y para ello se asienta, entonces, en la promoción de la democracia, es decir, su fin ya no es tan solo organizar la vida política del Estado sino, ante todo, la vigencia de los mecanismos de participación del ciudadano en las decisiones estatales que amplíen el espectro democrático, pues ya no solo basta la representación popular, tal como ocurrió en el estado de derecho legal, sino que ahora la participación popular entiende más canales y vías de expresión para que el sustrato democrático sea amplio y produzca más legitimidad en las decisiones estatales y, desde luego, en las constituciones o reformas constitucionales que se promulguen ${ }^{13}$.

13. En este sentido de ampliación del espectro de participación en el estado democrático de derecho, por ejemplo HABERMAS señala lo siguiente: "Con el paso de la sociación horizontal de ciudadanos que se reconocen recíprocamente derechos, a la forma organizativa de sociación vertical que representa el Estado, la praxis de la autodeterminación de los ciudadanos queda institucionalizada como formación informal de la opinión en el espacio público político, como participación política dentro y fuera de los partidos, como participación de procesos
Ahora bien, la amplitud democrática también responde a una natural consecuencia del trasegar de las sociedades humanas, cual es el de ser heterogéneas y plurales. De ello surgen variadas visiones y expresiones sociales que deben ser objeto de reconocimiento constitucional y por esto surge, como valor constitucional relevante, la igualdad efectiva, es decir, admitir las diferencias y sobre ello generar la igualdad para acceder a los derechos. Son estas caracterizaciones que sustentan, entonces, el estado democrático de derecho que, como se ve, enfatiza en la práctica extensa de la democracia, que incluye a todos los sectores e implica que, desde luego, el reconocimiento constitucional abarque todos los grupos y capas de la población.

En consecuencia, en este modelo de Estado, la democracia como práctica de diálogo entre todos los actores sociales, es la nota determinante que la distingue, es decir, que la soberanía proviene de la democracia, entendida como un proceso de encuentro y de diálogo, no como una imposición de clase como ocurrió en el Estado de derecho, o como imposición de ideologías como acaeció en el Estado liberal-conservador. Por el contrario, en este modelo democrático, el diálogo y la comunicación permiten integrar cada vez más al ciudadano en las decisiones estatales ${ }^{14} \mathrm{y}$, por ende, en la dinámica constitucional.

\section{EL ESTADO SOCIAL Y DEMOCRÁTICO DE DERECHO}

El origen histórico de este modelo de estado se ubica en las revoluciones que reivindicaban el amparo de los derechos de los sectores que, por su situación económica, no eran fácticamente destinatarios de las libertades y prerrogativas promulgadas en la constitución. Por esto, buscaron por medio de movimientos revolucionarios ser reconocidos mediante la implantación de nuevas reformas constitucionales. Así, por ejemplo, el ciclo revolucionario que comenzó en 1848 en Francia y de ahí irradió a Europa central, significó el sufragio universal, el reconocimiento de los derechos al trabajo, el salario y el de asociación, entre otros. Estas revoluciones perfilaron el reconocimiento y la necesidad de incluir dentro

electorales, en la deliberación y toma de decisiones de los Parlamentos, etc.", vid más en HABERMAS, Jürgen, Facticidad y Validez, Trotta, Madrid, 2010, p. 202.

14. Ver, Botero, 1999: 156. 
de la constitución derechos que, aunque ya se tuviera certeza de su contenido, como el derecho al trabajo, el salario o el de asociación, no habían sido efectivizados y tenidos como parte del orden jurídico ${ }^{15}$. Ahora bien, es cierto que el termino "social" se acuñó en esta época histórica, sin embargo, paradójicamente no fue sino hasta después de terminada la Segunda Guerra Mundial que adquirió relieve constitucional, pues detrás de las revoluciones sociales surgieron movimientos nacionalistas que desembocaron en autoritarismos, los cuales, si bien en algún momento significaron la mejora de condiciones y de dignidad para la clase trabajadora, también fueron un retroceso democrático. De ahí que, finalizada la guerra, se buscara que la igualdad para los ciudadanos se convirtiera no solo en principio sino en algo efectivo ${ }^{16}$.

Al margen de las finalidades ideológicas, el Estado social y democrático de derecho significa ante todo intervención del Estado a favor de los sectores y ciudadanos más débiles de la sociedad y por ello la preocupación por fijar un salario mínimo para todos, ampliar la cobertura de servicios públicos, de seguridad social y salud, asociación sindical, igualdad de impuestos, protección al trabajador y sobre todo protección de las clases menos favorecidas para alcanzar la igualdad en el acceso a los bienes y servicios tanto materiales como de índole espiritual ${ }^{17}$. En suma, Estado intervencionista pero en el sentido de protección del más débil mediante la categorización de los derechos sociales a rango constitucional, al igual que la creación de mecanismos de protección también caracterizados en la constitución. Ahora bien, esta clase de Estado asume importantes compromisos económicos para lograr sus fines sociales lo cual ha generado tensión con el capital y las empresas y, con ello, se predica la crisis del Estado social y democrático de derecho que cada vez recibe nuevos embates del poder económico, que no solo hacen temblar este modelo de estado sino también el mismo concepto de democracia ${ }^{18}$ y que es, entonces, la gran problemática del Estado en la época actual.

15. Ver, Zagrebelsky, 2016: 77

16. Ver más en Viciano y Martínez, 2017, p. 3 y s.s.

17. VidVer, en este sentido, ARAUJO RENTERIAAraujo Renteria, ob., cit., p. 360.

18. Ver, en este sentido, VICIANO y MARTINEZ, ob., cit., p. 7.

\section{LA CRISIS DE LA DEMOCRACIA EN EL CONSTITUCIONALISMO}

La evolución del constitucionalismo es, entonces, como lo apunta Zagrebelsky, la soberanía de la Constitución y con ello, toda ley queda supeditada, entonces, a lo dispuesto en el texto constitucional ${ }^{19}$. De hecho, los modelos de estado que fueron surgiendo en la época moderna tienen su fuente normativa en la Constitución. Con todo, el énfasis constitucionalista, aunque ha permitido avances y beneficios sociales, como en el estado social y democrático de derecho, también, paradójicamente ha determinado menos democracia. En efecto, si miramos bien, las reivindicaciones sociales conseguidas y plasmadas en la constitución surgieron por la necesidad de alcanzar una igualdad efectiva, pero actualmente, los sectores que a diario van surgiendo y van reclamando su espacio en la constitución ya no están en el ámbito de una democracia con sentido de nación con una idea común de progreso y bienestar, sino que participan de una idea democrática de grupos con necesidades focalizadas con apremio de reconocimiento constitucional. Si esto es así, el constitucionalismo no avanza por la práctica democrática, sino que marcha por su misma inercia, es decir, por virtud del mandato constitucional de la igualdad, se debe reconocer derechos a todos aquellos sectores menos favorecidos. Alguien podría decir que esa fue la intención del constituyente, es decir, que se haga efectiva la igualdad para todos. Sin embargo, el constituyente es dinámico y si queremos hablar de democracia, entonces, deben abrirse los espacios para que se exprese la voluntad popular o, de lo contrario, por más beneficio social que preste una norma, no podrá ser entendida como democrática.

Lo anterior, no significa cerrar los provechos que otorga el estado social, tampoco sugiere clausurar frente a las exigencias del neoliberalismo y sus políticas económicas, lo que se indica es abrir la participación democrática a todos los sectores para que no sean meros sujetos pasivos de la intervención estatal, sino que, por el contrario, se conviertan en actores de las políticas públicas y, por ende, gana la producción democrática en la configuración del constitucionalismo.

19. Ver, Zagrebelsky, 2016: 12. 
Ahora bien, es cierto que existen dificultades materiales para lograr los fines del Estado social y democrático de derecho y que también obstaculizan la plenitud del constitucionalismo social, sin embargo, ello obedece a las crisis económicas y a los naturales desencuentros de las ideologías en pugna y a la larga tendrán su manera de solución, pero lo que siempre estará en crisis para predicar un constitucionalismo será la democracia, de hecho, será preferible renunciar a la constitución pero no al espíritu democrático. En este contexto, por ejemplo, Martínez Dalmau previene de no traducir voluntad de la mayoría como voluntad popular ${ }^{20}$, así mismo, Vigo señala como la voluntad popular queda sujeta a la voluntad de los Tribunales Constitucionales ${ }^{21}$. Todos estos son problemas de la democracia o más bien, de como el constitucionalismo va cerrando espacios para que la democracia se exprese.

Las constituciones no pueden quedarse estáticas en paradigmas que en determinado momento resultaron relevantes, no fueron creadas para permanecer inmóviles e incólumes, pues no debe olvidarse que su creación fue producto de un determinado momento histórico que tampoco es eterno y por ello, es natural que haya cambios. Por tanto, la democracia es el vehículo que permite avanzar en el constitucionalismo. En efecto, no puede dejarse todo el desarrollo del constitucionalismo en los pronunciamientos judiciales o en la práctica legislativa. La manera como renueva sus contenidos la Constitución es en el florecimiento de la práctica democrática. Dicho esto, conviene, entonces, hacer una breve reflexión en torno a la democracia.

\section{LA RELACIÓN DEMOCRACIA Y CONSTITUCIONALISMO}

En nuestra época la democracia también necesita renovar su sentido, ya no es suficiente decir que el pueblo se expresó para predicar el carácter democrático de una decisión; tampoco es sostenible afirmar que estamos haciendo democracia cuando participamos en las elecciones. Sin duda, existe participación ciudadana, pero la práctica democrática exige del ciudadano más que la defensa de ideologías, lo que reclama es, superar las contradicciones que

20. Ver, Martinez Dalmau, R., 2018: 90

21. VIGO, Rodolfo Luis, ob., cit., p. 276. se presentan al momento de decidirse por alguna propuesta política, es decir, valores y conciencia.

En este sentido, Zagrebelsky pone de relieve si el conocimiento serviría para fundar la practica democrática como virtud al estilo de los antiguos griegos y concluye de manera negativa, en cuanto la conciencia no coincide necesariamente con un conocimiento recto y ahí no puede haber virtud ${ }^{22}$, lo cual no haría entonces virtuoso al ciudadano para la practica democrática. Perdida esta opción, entonces Zagrebelsky acude a la utilidad que pueda representar la democracia y, en este caso, concluye que incluso la gente puede renunciar a la misma democracia cuando se trata de proteger bienes comunes como la pacifica convivencia o la seguridad publica y dejar las cosas en manos de un salvador para que decida por todos nosotros ${ }^{23}$.

A pesar de ello, la democracia seguirá siendo la manera mas objetiva y garantista de formación del poder público y, desde luego, de la constitución. Nuestra época después de ver las guerras mundiales y dictaduras de todo orden puede encarar la democracia como un debate, un encuentro, espacios libres de opinión, sin coacciones y sin imposiciones ${ }^{24}$. Ello nos lleva a un valor que pasa desapercibido en la practica política y que, el constitucionalismo, tiene como fuente de sus decisiones, cual es de la dignidad humana y que, en términos de practica democrática implica el respeto de uno mismo que conlleva al respeto por el prójimo ${ }^{25}$.

A partir de esta idea, se puede colegir que un régimen que no practique este respeto no puede ser tenido como democrático, como ocurre en aquel en el que no se puede expresar alguna opinión respecto de las cosas del Estado o el que también se descalifica la opinión del otro. De igual modo, un debate político en el que los

\footnotetext{
22. Zagrebelsky, 2010: 112.

23. Ver, Zagrebelsky, 2010.

24. En este sentido, Zagrebelsky, apunta lo siguiente: "La democracia es un dialogo paritario $y$, si quiere seguir siendo tal, debe desarrollarse deponiendo todo instrumento de presión. En primer lugar, la presión material, como la que viene de la violencia y de las armas; $y$, en segundo lugar, también la presión moral, como la que se puede ejercer en la relación asimétrica de autoridad-sujeción que se crea cuando las relaciones entre padres e hijos, entre maestros y discípulos, degeneran en autoritarismo. Una relación que puede llevar a la falta de respeto y a contradecir la libertad y la democracia", Zagrebelsky, 2010: 113.

25. Ver, Zagrebelsky, Gustavo, ibid.
} 
participantes no tengan en cuenta dicho respeto tampoco puede predicarse como democrático. En suma, el respeto por sí mismo y por el otro, es una exigencia natural que se le hace al ciudadano cuando participa en la esfera política y más aún en la formación del texto constitucional.

Además de esto, también cabe anotar que, hoy en día, la participación del ciudadano en las decisiones políticas se ha reducido por cuanto cada vez se siente menos importante frente a la omnipotencia del poder estatal, el cual, a su vez, ha sido capturado por políticas económicas particulares que han minado la posibilidad de decidir de la población por cuanto también operan políticas de exclusión, lo cual deja la dinámica de la democracia en manos de muy $\operatorname{pocos}^{26}$.

Esta situación, desde luego, no es novedosa $\mathrm{y}$ de hecho se advierte que una de las grandes debilidades de un régimen democrático será la participación real de la ciudadanía en las decisiones de Estado. Lo que ocurre es que la tendencia a no participar es un fenómeno que se ha incrementado en el mundo contemporáneo o, en mejores palabras, el ciudadano solo se siente un mero elector con un tremendo miedo frente a la acción del Estado, de ahí que la democracia se sienta como algo remoto y alejado de la actividad normal del ciudadano ${ }^{27}$. Dicho fenómeno aumenta su déficit en el continente latinoamericano, lo cual ha llevado a una distorsión del constitucionalismo,

26. En este sentido, es bastante ilustrativa la descripción que hace Touraine del debilitamiento de la democracia: " La conciencia de ciudadanía, ya sea porque muchos individuos se sienten más consumidores que ciudadanos y más cosmopolitas que nacionales, ya porque, al contrario, cierto numero de ellos se sienten marginados o excluidos de una sociedad en la cual no sienten que participan, por razones económicas, políticas, étnicas o culturales. La democracia así debilitada, puede ser destruida, ya sea desde arriba, por un poder autoritario, ya desde abajo, por el caos, la violencia y la guerra civil, ya desde sí misma, por el control ejercido sobre el poder por oligarquías o partidos que acumulan recursos económicos o políticos para imponer sus decisiones a unos ciudadanos reducidos al papel de electores" Touraine, 2006: 16

27. En este sentido RUSSELL anota lo siguiente: "El elector ordinario, lejos de considerarse a si mismo el origen de toda la fuerza del ejército, de la marina, de la policía y de la burocracia se siente su humilde súbdito cuyo deber es como suelen decir los chinos, temblar y obedecer. Mientras la soberanía democrática sea remota y poco frecuente, en tanto que la administración pública este centralizada y que la autoridad se delegue del centro hacia la circunferencia, será difícil evitar ese sentimiento de impotencia individual frente a los poderes existentes. Y, sin embargo, debe evitarse esa sensación de impotencia si queremos que la democracia se una realidad para el espíritu y no meramente una realidad para el aparato gubernamental" Russell, 2005: 75 . pues, desde el populismo y el caudillismo se hacen constituciones $\sin$ democracia $^{28} \mathrm{y}$, en este sentido, la situación se torna mas delicada pues la desigualdad y la pobreza en este parte del mundo hacen que, junto a los problemas sociales existentes, la democracia se convierte solamente en un discurso sin correspondencia con la realidad. En este sentido, el mejor de los mundos posibles, es aquel en el que, desde la constitución, los fallos judiciales proyecten tendencias igualitarias y proteccionistas de los desfavorecidos y, con el paso del tiempo, se internalice esa conciencia en la sociedad.

Así las cosas, el imperio de la constitución que estamos ahora viviendo, ha significado una proyección positiva y de mejora para la humanidad, pues, de los movimientos revolucionarios se fueron tomando e incorporando conquistas que fueron plasmadas como derechos en la normatividad constitucional. Este desarrollo muestra el origen emancipatorio y revolucionario que ha tenido el constitucionalismo, pero también muestra la posibilidad de los individuos de lograr consensos en la protección de derechos para llevarlos a su caracterización constitucional, situación que viene aprendida, sobre todo después de la posguerra. Con todo, los movimientos impositivos y negadores de la libertad inspirados en populismos de toda clase de ideologías siguen presentes y constituyen un serio peligro para el constitucionalismo y, más aún, para la vida democrática de los países de esta parte del mundo.

\section{LA REALIDAD DE LOS VOTANTES: FUTURO DE LA DEMOCRACIA Y DEL CONSTITUCIONALISMO}

Son muchos los cuestionamientos que se le pueden enrostrar a la democracia $\mathrm{y}$, sobre todo, si en ella se originó el constitucionalismo, pero lo cierto es que en la democracia está puesto el futuro del desarrollo constitucional. Ahora bien, esta relación puede ser más estrecha y fructífera en cuanto se entiende que la democracia no es únicamente la puesta en marcha de un sistema representativo y de participación popular en el poder político ${ }^{29}$, pues, en esa dirección, desde luego que el constitucionalismo terminará

28. Ver, en tal sentido, Martínez, 2018: 207 y s.s. 29. Así parece entenderlo Ruiz Miguel, A., 2004: 51. 
interpretando los valores de las elites dominantes, en cuanto un sistema representativo no garantiza la participación del pueblo en las decisiones políticas $^{30}$.

También, somos conscientes de la división social existente en la actualidad y que lo que hace es que a las clases dominantes corresponda la creación y el desarrollo del poder político en tanto que las clases oprimidas por la desigualdad y la pobreza no se sientan participes del poder político y, por esto mismo, no se interesen por hacer parte de la participación ciudadana ${ }^{31}$ y con ello también sale debilitada la democracia y, con mayor razón, queda el constitucionalismo en manos de la interpretación de las elites.

Con todo, existen perspectivas de índole comunicativa que ve en los medios una oportunidad para que la gente se integre a la práctica democrática, en el sentido que existe una mayor cobertura de información y comunicación para el pueblo, en desmedro del conocimiento que en otra época solo era de acceso para las elites, lo cual es un signo alentador por cuanto las masas deciden por si mismas en contrariedad a lo ordenado por la elite dominante ${ }^{32} \mathrm{y}$, de ahí, puede surgir un cambio de papeles para que, finalmente la ciudadanía se apropie de su realidad y lleve sus intenciones a la decisión política mediante la democracia; es decir, si podría ser posible, entonces, la realización de la democracia que tendría repercusiones saludables en el constitucionalismo, en tanto y en cuanto, da cuenta de la voluntad de los destinatarios de la justicia constitucional.

La crisis democrática, además de representar en sí misma un desafío para el constitucionalismo, también muestra unas problemáticas más profundas que, igualmente, afectan al desarrollo constitucional. En efecto, la desigualdad y la pobreza, que adquieren notas crónicas en Latinoamérica, conducen a entender que, si esas barreras no se superan, siempre la democracia será de un desarrollo frágil y populista y, por su parte, la justicia constitucional siempre estará

30. En este sentido, por ejemplo, José Luis Diez Ripollés denuncia la contrariedad que representa para el espíritu democrático cuando solo se deja la decisión en las elites (Diez Ripolles, 2003: 197).

31. Ver, Honneth, A., 2011: 61.

32. Ver, Duran y Nieto, 2007: 286. en peligro de ser asaltada por la efervescencia y la coyuntura política. Por otra parte, también a nivel europeo, las libertades civiles y políticas consagradas en la constitución también sufren los embates de ideologías neoliberales ${ }^{33}$ y de movimientos nacionalistas de tendencia excluyente, cuya fuerza puede incidir de manera negativa en las conquistas constitucionales logradas hasta el momento. Así las cosas, estando la democracia cercada por todos lados, deberá encararse 0 , mejor todavía, desarrollar la practica democrática de un modo que se acerque al ciudadano, que lo haga sentir participe y decisor efectivo en la dinámica política y que conduzca a que el sentimiento de ciudadanía crezca mejor y más.

En este sentido, desde luego, a modo propositivo, podría considerarse que las decisiones de la justicia constitucional también sean resultado de una consulta democrática ${ }^{34}$, pues ello haría que continuamente el ciudadano se vea en la situación de decidir realmente, es decir, que su votación ya no está por la elección de un representante, sino que, esta vez, en realidad, su aporte decisional si tiene que ver de manera directa con los asuntos del Estado y, más importante, sobre la decisión acerca de los contenidos de los derechos fundamentales. Sin embargo, esto podría abrir las puertas a partidos o movimientos que defiendan posiciones retrogradas que intenten acabar con las conquistas del constitucionalismo. Aunque es posible, en todo caso las elecciones mostrarán el estado de cosas de la sociedad y lo que necesita para convivir, decisión esta que no puede solo atribuírsele a los tribunales constitucionales, es también necesario consultar con la ciudadanía que cosas desean para su sociedad.

Lo anterior nos conduce, entonces, a poner sobre la mesa de la discusión democrática las predilecciones de la ciudadanía, entendidas en términos concretos. Por ende, la inquietud que surge es buscar la manera en la que se puede conectar la teorización político-constitucional con aquello que al ciudadano realmente le interese, pues la crisis democrática de la actualidad necesita de las propuestas de la teoría, pero en

33. Ver, Viciano y Martínez, 2017: 7.

34. Ver, Ruiz, A., 2004: 77. 
tanto y en cuanto puedan integrarse a la realidad del ciudadano ${ }^{35}$.

En efecto, como se ha venido señalando a lo largo de este escrito, la crisis de la democracia es la característica que tiene que afrontar el constitucionalismo $\mathrm{y}$, en esta dirección, resulta más profunda aún, cuando los grandes temas constitucionales no son objeto del diario vivir del individuo. Por tanto, la reflexión debe dar cuenta de lo dinámico de la sociedad y, en este sentido, es importante tener un acercamiento con los valores, tendencias o inclinaciones de los electores, pues ellos son los que con su participación transforman el desarrollo constitucional. De allí surgen nuevos valores y además nuevas valoraciones respecto de las cosas antiguas, y ello no se puede rechazar, hay que asimilarlo como los contenidos por los cuales discurre la democracia. Así, la sociedad de hoy plural y laica, permeada por nuevas conceptuaciones en todos los aspectos vitales, descreída de los liderazgos, más preocupada en el éxito individual, abierta a nuevas caracterizaciones de la religión y la sexualidad, indigenista y ecológica, entre otras, constituye el nuevo abanico de preocupaciones que tiene el ciudadano y sobre las cuales la democracia debería sur vehículo legítimo de expresión ${ }^{36}$.

Por lo anterior una teoría del constitucionalismo no puede prescindir de la democracia y esta, a su vez, no puede ignorar los movimientos que de todo orden se dan dentro del seno social $y$, por esto mismo, los contenidos de la democracia y del constitucionalismo serán aquellos que en su momento la sociedad considere. También, aquí algunos autores podrían señalar que en, muchas ocasiones, la sociedad no sabe que es lo mejor para ella y que bastaría ver el irracionalismo pasional de los votantes en la Alemania nazi o, guardadas las distancias, en la Colombia de Uribe.

35. En este sentido: "Las discusiones acerca de reformas constitucionales, el parlamentarismo, la democracia y otros temas acerca de lo público que quitan el sueño a muchos teóricos y cientistas políticos, son muy importantes para el mantenimiento y desarrollo de la democracia, pero no hay razón para que los electores comunes se interesen en ellas.", Duran y Nieto, 2007: 375.

36. Así lo expresan Duran y Nieto: "No se puede llegar con los viejos mensajes y con las antiguas formas de comunicación a ese nuevo elector, del que hablamos en la primera parte de este trabajo, más independiente, informado, lúdico, individualista pragmático, socializado en una familia democrática, fruto de una sociedad feminizada, que ha superado muchas de las taras machistas del siglo pasado" (2007: 279).
Con todo, cabe advertir que lo que se exige es la posibilidad que las instituciones abran los espacios a los nuevos valores que se van dando en la sociedad y que se expresen en democracia, pues, una democracia no es de partidos, sino de ciudadanos. Si esto es así, desde luego que sí es posible admitir la injerencia del canal democrático en los pronunciamientos de las jurisdicciones constitucionales. Sin embargo, ello solo puede alcanzarse en cuanto exista la igualdad para participar no solo en las elecciones, sino en la misma formación y debate de los contenidos en todos los espacios públicos, el ciudadano no solo es un elector, es constructor de las decisiones políticas con vocación de cobertura en todos los sectores y que no solo se quede en el mero desarrollo parlamentario ${ }^{37}$.

\section{EL ACCESO A LOS DERECHOS: EL CAPÍTULO DEFINITIVO DEL CONSTITUCIONALISMO}

Sentada la crisis democrática y la puesta en la mira del nuevo electorado que va surgiendo conforme se van renovando y cambiando las visiones de vida y los valores, surge de ello, una cuestión que a la larga implicara el quiebre de la práctica democrática. Me refiero a los problemas de desigualdad para el reconocimiento y accesibilidad de derechos y de recursos, pues, con efectividad de derechos plenos, sin discriminaciones de ninguna índole, puede el ciudadano participar en la sociedad y decidir si es su intención participar o no. Pero en una sociedad que solo permita a una pequeña parte de la población intervenir en las decisiones políticas y, desde luego, en los pronunciamientos constitucionales, siempre estará en déficit democrático $y$, por ende, el desarrollo constitucional no estará aparejado a las reales demandas del ciudadano.

Esta es la faz realista de la sociedad de hoy y a la que el constitucionalismo debe mirar para estructurar sus respectivas formulaciones teóricas. Así, por ejemplo, señala Fraser que el desigual reparto de las riquezas junto con la

37. Al efecto escribe Habermas: "Los discursos públicos solo tienen resonancia en la medida en que se difunden, es decir, sólo bajo condiciones de participación extensa y activa, y a la vez, diseminante y dispersante. $Y$ esta exige, a su vez, el trasfondo de una cultura política igualitaria, desnuda de todo privilegio debido a educación, de una cultura que se haya intelectualizado a todos los niveles y en toda su amplitud" (2010: 616). 
ausencia del reconocimiento de los derechos para todos, se presentan como la cara negativa de la economía, generando divisiones e injusticia social ${ }^{38}$. Estas situaciones que han sido objeto de enconadas disputas teóricas, también pueden resolverse desde la inclusión de los paradigmas populares de justicia para defender la redistribución y el reconocimiento ${ }^{39}$ bajo el entendido que estos conceptos constituyen las luchas que ocurren hoy en día en la sociedad civil.

De esta manera, los movimientos populares abarcan más reivindicaciones, a sabiendas que, de hecho, las injusticias sociales provienen tanto de la ausencia de reconocimiento como de la falta de redistribución de recursos. Además, la injusticia social también surge en los patrones de vida cultural institucionalizados en la sociedad que impiden la participación igualitaria de todas las personas en la vida social, por ello, la reparación no está en el daño físico como tal sino en crear unos patrones nuevos que favorezcan la igualdad de las personas en la participación en la sociedad $^{40}$.

Por esto surge como relevante el concepto de paridad participativa, que significa la interacción de todos los miembros de la sociedad en pie de igualdad, pero favorecido tanto por una distribución de recursos y unos patrones culturales que garanticen la independencia económica necesaria para participar, al igual que la oportunidad de interactuar en la vida social para conseguir la estima social ${ }^{41}$. Y si la injusticia social implica la negación sistemática de participación por parte de los patrones de cultura institucionalizados, entonces, la reivindicación social es, precisamente, reconocer los caracteres distintivos de los grupos para que desde el prisma de la paridad puedan participar de la vida social $^{42}$. Con esto queda claro que también los patrones culturales, reforzados por el sistema económico de la industria y del libre mercado, han impedido satisfacer los requisitos de la justicia para todos y quizá la solución esté en el cambio de patrones culturales de vida para que sea exitosa

38. Ver, FRASER Nancy, HONNETH, Axel, ¿Redistribución o reconocimiento? Morata, Madrid, 2006, p. 28 y s.S.

39. Ver, FRASER, ob., cit., p. 23.

40. Ver, Fraser, 2006: 37.

41. Fraser, 2006: 45 y s.s.

42. Fraser, 2006: 50. la redistribución de recursos y el acceso efectivo a los derechos.

No obstante, no todo se puede reducir a un cambio de patrones culturales, es también un problema de un mundo de producción, funciones, industria y burocracias en donde el sujeto debe lograr unas condiciones materiales y gozar del disfrute de sus derechos, que el mundo industrializado niega encauzando al hombre en una dirección y señalándole una calidad de vida. Lo anterior, da cuenta de lo significativo de la denuncia de las injusticias sociales que a lo largo del tiempo se han venido cometiendo contra los grupos más vulnerables y desfavorecidos, situación que, si bien fue foco del constitucionalismo, se convirtió en una constante.

Además, en la creación de las normas es obvia la participación de grupos e intereses que se mueven en un marco político. Este proceso está lejos de pensar las leyes en términos de democracia. Esta es, actualmente, una enorme dificultad que no hace más que acrecentarse en cuanto a cada momento surgen nuevos intereses, grupos, sectores y protagonistas de la política que modulan el constitucionalismo en su propio beneficio.

Ahora bien, si la práctica política modifica el sentido de la constitución, entonces, en este mismo contexto debe ubicarse un concepto tal de democracia que alcance al mayor número de personas. Este contexto, no puede abordarse, por ejemplo, desde una teoría social fundamentada en el análisis del poder de la sociedad y en la capacidad de éste para influir en la conducta del individuo mediante la obediencia a determinadas pautas sociales, pues, ignora los particulares grupos o micropoderes que también intervienen en la dinámica vital, sea social o sea individual ${ }^{43}$. Por tanto, el sentido de democracia pertenece a la sociedad, entendida de la manera más concreta posible. Es decir, no se va a entender la sociedad como un abstracto cuyas categorías dependen de un modelo teórico estandarizado y uniforme. En consecuencia, el contenido constitucional se entenderá desde la realidad de la sociedad, de sus vivencias, de sus múltiples contenidos, en fin,

43. Es una conclusión que se colige de la enorme influencia que han ejercido las posturas unilaterales de la sociedad y que precisamente, fundamentan en un todo abstracto e impersonal el particular desenvolvimiento de las biografías humanas, tanto en lo colectivo como en lo individual. Giddens, 1997: 230. 
de dar cuenta de todos sus componentes, pues un concepto de justicia desarrollado en la propia realidad social es más legitimo para que el Estado la administre.

\section{LA IDIOSINCRASIA NACIONAL COMO CRISIS DE LA DEMOCRACIA Y DEL CONSTITUCIONALISMO Y LA RESPUESTA EN EL LENGUAJE}

Basados en lo anterior, cabe entonces hacer una mirada a la sociedad colombiana, en orden a finalizar con los particulares desafíos que existen para el constitucionalismo y la democracia en nuestro país. Así, se puede decir que, en líneas generales, la no presencia del Estado y el consiguiente estado de anomia de la sociedad colombiana propiciaron el origen y desarrollo de la nación colombiana. En efecto, una primera caracterización es la poca o escasa importancia que el pueblo colombiano le da a su pasado ${ }^{44}$, esta impronta tiene como consecuencia buscar respuestas impensadas e inmediatas para solucionar un problema. Esto explica que en trescientos años de vida republicana, hayamos tenidos más de diez constituciones, también con más de diez reformas constitucionales ${ }^{45}$. Aquí se expresa el afán de olvidar y sepultar un pasado creyendo en el poder de la legalidad, que siendo tan apresurada apenas si deja tiempo para su aplicación cuando ya se está convocando a una nueva reforma.

Esta característica de la nación colombiana que, como se ve, proyecta sus efectos en la constitucionalidad y en la legalidad y desde luego, en su visión democrática, refleja la prontitud por ocultar un pasado vergonzoso o insignificante ${ }^{46}$. De este modo, los derechos y prerrogativas constitucionales junto con la práctica democrática, no podrán aplicarse con naturalidad, en cuanto no se asuma en realidad el pasado que originó y en el que se desarrolló la nación, por eso, es necesario fijarnos en el pasado de la nación no en el del Estado colombiano, pues esconder la historia de la nación detrás de la historia del Estado es una falacia ${ }^{47}$ y si esto es así, entonces, toda nueva constitución o reforma constitucional

\footnotetext{
44. Serrano, 2016: 17

45. Ver, entre otros, Henao (1998) y Sachica (1994).

46. Serrano, 2106.

47. SERRANO, Enrique, ob., cit., $p 18$.
}

que se pretenda implantar, no tendría validez en relación con la historia que la nación ha vivido, pues no responde de manera efectiva al recorrido histórico y actualizado de sus habitantes, sino que solo sería una aplicación de una legalidad coyuntural y ahistórica que no resuelve los reales conflictos sociales del Estado colombiano.

Otra caracterización importante que trae dificultades para aplicar una constitución democrática es una habitual desconfianza de la población que impide, entonces, llegar a acuerdos. Esto pone en duda, incluso, un proyecto de nación ${ }^{48}$. En este aspecto, es relevante integrar posiciones para tratar de expulsar el individualismo de la nación colombiana, pero no como parte de un proselitismo constitucional, al contrario, debe buscarse derrumbar el egoísmo, situación que es un obstáculo grave para fundamentar un gran acuerdo que sustente una verdadera constitución. Ahora bien, los dos aspectos anotados, pueden ser superables, sin embargo, subsiste un tercero que definitivamente puede ser una barrera infranqueable para la realización de una justicia democrática y constitucional.

Se trata del carácter desinstitucionalizado de la sociedad colombiana, en efecto, la mediocridad, la anomia, la conveniencia, el menor esfuerzo, la ostentación, el acomodo y la mentalidad de corto plazo constituyen el ethos de la sociedad colombiana $^{49}$. Y es en este ethos, en el que la justicia constitucional tiene que actuar. Por ello, toda normatividad, desde la superior hasta las del grado inferior, que no tenga en cuenta estos aspectos, va a fracasar. No se trata de cuales derechos se admitan y puedan resolverse, en caso de conflicto, dentro de la constitución; por el contrario, se trata de reconocer las características de una nación para que se pueda implementar una constitución.

Así las cosas, para hacer la conceptualización de una práctica democrática con resultado constitucional, hay que observar el sustrato

48. SERRANO lo describe de la siguiente manera: "Igual que ya se ha diagnosticado en otras ocasiones con este análisis se puede apreciar que este grupo de 47 millones de habitantes, compuesto por muchos individuos desconfiados, tiene grandes dificultades a la hora de construir consensos y un proyecto colectivo de nación que la pudiera perfilar de una manera creíble y coherente en el futuro" SERRANO, Enrique, ibid, p 271.

49. Ver más en SERRANO, ibid p. 246 
nacional existente, hay que entender la nación para luego formular soluciones. En esa dirección, debemos ser conscientes que la sociedad colombiana adolece de problemas estructurales que le impiden conformarse como nación, al igual que obstaculiza la homogeneidad y realización de proyectos y acuerdos constitucionales.

En efecto, la apatía frente al mundo y a los demás induce a no tener conciencia de la historia, incluso de la más reciente, con lo cual todo esfuerzo institucional carece de legitimidad por cuanto, de esto se concluye, a la nación colombiana poco le importa estas cuestiones.

En consecuencia, la pregunta acerca de una constitución pasa por responder primero a cuál sociedad se le está proponiendo. Ello sugiere, entonces, la inclusión de la nación en la dinámica de la solución, no como concepto, sino en términos reales. Sería bastante positivo, por ejemplo, en el caso de propuestas de reforma constitucional, que se le dé entrada a la práctica democrática concretada en la realización de diálogos regionales, pues, la nación colombiana se explica en regiones $\mathrm{y}$, cada una, mostrará diferentes pretensiones de aquello que quiera sea incluido en la constitución, cuestión esta que siempre ha sido olvidada pues el nivel central adopta los conceptos y toma las decisiones dejando en el margen el fundamento regional que dota de significado a todas las problemáticas sociales.

Anotada la crisis en la que estamos y cómo esta ha logrado expandirse y mantenerse, entonces urge hallar el modo de resolver, entonces, el problema fundamental que surge de la idiosincrasia del ser colombiano, de sus dificultades para afrontar esa realidad que le pertenece, de sus tragedias, de cómo se instala $\mathrm{y}$ se posiciona en este trance de violencias $\mathrm{y}$ sinrazón y de cómo, por medio de su pensamiento, puede comprender y proponer soluciones que signifiquen consolidación de la democracia y acceso a la justicia constitucional.

Parafraseando al maestro Carlos Gaviria, la filosofía ha tenido como su dominio el problema radical del hombre frente al mundo ${ }^{50}$ y aquí el problema es del hombre colombiano en este ámbito geográfico denominado Colombia. Y si bien es cierto que, si hablamos de democracia

50. Ver Gaviria, 2018: 52 y de constitución, lo natural sería el análisis de la ciencia política, también es cierto que, en un contexto determinado, se examina una realidad nacional que implica un estudio de valores que se practican y defienden en la sociedad, por tanto, dicho estudio no puede ser de dominio exclusivo del abordaje político o constitucional, pues ello no daría cuenta de todo el problema. En este sentido, ya mencionaba Russell que las cuestiones de valor no pasan por las ciencias, y colocaba como ejemplo que la ciencia no podía probar si es malo gozar con la aplicación de un tormento, por eso estos temas valorativos quedan por fuera de su dominio $^{51}$

Así las cosas, ¿hacia donde mirar?, ¿qué clase de análisis filosófico será válido para entender nuestra realidad nacional? En primer lugar, si la cuestión es de valores, entonces, se puede predicar acerca de su vigencia o de su caída, sin embargo, en cuanto vimos que existe una práctica de conveniencia y doble moral, luego el tema no es posicionamiento de los valores sino de cómo son interpretados por parte de la población.

Desde esta perspectiva surge como necesario hacer una crítica del lenguaje puesto que, si existe ese doble juego valorativo basado en la oportunidad y en la conveniencia, entonces la interpretación será vacía o carente de sentido en cuanto los contenidos de los valores serán usados de manera arbitraria y de lo cual vendrán las correspondientes contradicciones en la vida diaria. Por eso, el lenguaje en el que se expresan los valores constituye el punto de análisis.

Ahora bien, el análisis lingüístico implica que todo nuestro mundo, o mejor la manera como interactuamos con él, es de carácter fundamentalmente verbal, este es uno de los fundamentos de la filosofía del análisis lógico ${ }^{52}$ que, precisamente, evidenció el problema del lenguaje como método para entender el mundo. Esta escuela filosófica guarda por ello relación con el planteamiento de Wittgenstein en cuanto también ve el mundo a través de los usos del lenguaje y, desde luego, también con las formulaciones de $\operatorname{Kraus}^{53}$. Así las cosas, es claro que el estudio del lenguaje es útil en orden a descubrir las contradicciones de la mentalidad

51. Ver Russell, 1984: 458.

52. Russell, 1984: 453.

53. Gaviria, 2018: 30. 
formalista y de la doble moral del pueblo colombiano.

De hecho, las grandes teorizaciones con pretensiones de dar cuenta de toda la realidad conllevan, en la gente, a la tendencia de opinar desde la presunta solidez de un edificio teórico fuertemente construido y, de esto al fanatismo, solo hay un paso. Por esta razón, en el análisis del lenguaje, se evidencia la verdadera intención de las palabras que ya no pueden esconderse detrás de una pureza teórica o en la barrera metafísica. Además, esta clase de análisis, al no comprometerse con una ideología o una moral, que solo ve la expresión verbal como objeto de estudio, resulta menos prejuiciosa y más adecuada con la veracidad y honradez intelectual que debe presidir todo esfuerzo científico o filosófico.

En consecuencia, desde allí es posible el estudio y las posibles soluciones al problema del inmovilista formalismo desde la ausencia del imperio de la ley, la doble moral, la no internalización de valores, la ampliación desmedida del exacerbo de ánimos, la banalización de los planes de acción políticojurídicos y la descarada, pero sutil, incitación al odio por parte de los grandes medios. Si todo se pasa por el estudio del universo del lenguaje que se usa en nuestro contexto, entonces se explica, en buena parte, la crisis de la democracia que incide en el constitucionalismo. Línea que ha sido la que atraviesa el presente ensayo.

\section{CONCLUSIÓN}

Como al inicio fue señalado, la crisis democrática no significa únicamente la dificultad para el disfrute efectivo de derechos y libertades o que sea el óbice para el asentamiento de la realidad del Estado democrático social y derecho como producto último del mas reciente constitucionalismo. También la crisis es la que hace avanzar a los Estados y ha fundamentado el alcance y cubrimiento de más derechos y libertades para una mayor parte de la población.

Esta crisis de democracia que, en el contexto latinoamericano y ya particularmente en el colombiano, se agudiza con la vigencia del populismo, ha hecho que sean los tribunales constitucionales los que tomen las decisiones por el constituyente primario lo que, a la larga, también implica un déficit democrático.

Por ello, del análisis expuesto es concluyente que se necesita más democracia en todas las decisiones que afecten a la comunidad, no solo como realidad electoral, sino también que se busque un mejor modo de participación democrática en las decisiones jurídicoconstitucionales. Se precisan de mecanismos democráticos coetáneos con las sentencias que vayan más allá de recoger los planteamientos de la comunidad en el respectivo fallo, pues, de cualquier modo, el poder judicial termina remplazando al constituyente original.

Finalmente, se debería continuar por la senda democrática como explicación del constitucionalismo para que, de esta forma, las constituciones no olviden su origen democrático $\mathrm{y}$, mucho menos, los pronunciamientos jurídico-constitucionales basen sus fallos a los lineamientos del soberano popular. Solo de esta manera la democracia puede cumplir su función de expresión y de renovación de las instituciones, en cuanto da cuenta de la realidad de los votantes $\mathrm{y}$ de sus aspiraciones. 


\section{BIBLIOGRAFÍA}

- Araujo Renteria, J. (2015). Filosofía o Teoría del Derecho Constitucional. Bogotá: Editorial Ibáñez.

- Arranz Notario, L. (1998). El liberalismo Conservador en la Europa Continental 1820-1939. Revista de Estudios Políticos (102), 59 - 76.

- Botero Uribe, D. (1999). Teoría social del derecho. Bogotá: Universidad Nacional de Colombia.

- Cassirer, E. (2013). El mito del Estado, trad. Eduardo Nicol. México: Fondo de Cultura Económica.

- Duran Barba, J. y Nieto, S. (2007). Mujer, sexualidad, internet y política. México: Fondo de Cultura Económica.

- Fraser, N. y Honneth, A. (2006). ¿Redistribución o reconocimiento? Madrid: Morata.

- Gaviria Diaz, C. (2018). 9 Conferencias. Medellín: Señal Editora.

- Giddens, A. (1997). Política, sociología y teoría social. Barcelona: Paidos.

- Habermas, J. (2010). Facticidad y validez. Madrid: Trotta.

- Henao Hidron, J. (1998). Panorama del derecho constitucional colombiano. Bogotá: Temis.

- Honneth, A. (2011). La sociedad del desprecio. Madrid: Trotta.
- Martinez Dalmau, R. (2018). ¿Han funcionado las Constituciones del nuevo constitucionalismo latinoamericano? Lima: Derecho y Sociedad.

- Ruiz Miguel, A. (2002). Una filosofía del derecho en modelos históricos. Madrid: Trotta.

- Russell, B. (1984). Historia de la filosofía, $\mathrm{t}$ II. Madrid: Espasa Calpe.

- Sachica, L. C. (1994). Nuevo Constitucionalismo Colombiano. Bogotá: Temis.

- Serrano, E. (2016). ¿Por qué fracasa Colombia? Bogotá: Planeta.

- Touraine, A. (2006). ¿Qué es la democracia? México: Fondo de Cultura Económica.

- Viciano Pastor, R. y Martínez Dalmau, R. (2017). Crisis del Estado social en Europa y dificultades para la generación del Constitucionalismo social en América Latina. Revista General de Derecho Público Comparado (21), 1-19.

- Vigo, R. (2012). Constitucionalización y Judicialización del Derecho. Bogotá: Pontificia Universidad Javeriana-Grupo Editorial Ibáñez.

- Zagrebelsky, G. (2010). Contra la ética de la verdad. Madrid: Trotta.

- -----. (2016). El derecho dúctil. Madrid: Trotta. 